\title{
Systems thinking: embedding closure planning within the management operating system is the key to drive closure performance
}

HWB Lacy Stantec, Australia

M Slight Mike Slight and Associates, Australia

A Watson Stantec Consulting Services Inc., USA

\begin{abstract}
Miners worldwide are making large investments in innovation with a view to developing safe, efficient, and more productive mines. This in the face of a decline in ore grades, situated deeper, in challenging geographies and settings. Some miners are making very long-term investments in the management of future closure costs through careful planning and execution designed to protect the balance sheet. However as demonstrated by the recent Brumadinho tailings dam failure in Brazil, even partially "closed" facilities pose significant risk. This shows us that planning and properly executing closure measures during operations as a life-of-mine process is imperative if we are to sustain the industry and provide ongoing support of the communities where we operate.
\end{abstract}

While operational innovations are receiving a great deal of attention to contain operating costs, the effort to keep a lid on the post-mining costs has not been as effective. However, there are exceptions and "integrated mine closure" is becoming more prevalent as a goal of industry. This paper explores the measures that need to be taken by mining companies to impose rigour on the closure planning and provisioning process, with the intention of both planning for closure, and in accounting for closure liabilities more effectively. This will be a dramatic departure from "free cash flow" optimisation, but may point the industry to a more sustainable future across its stakeholder base.

Management Operating Systems (MOS) are well established in the mining industry, but are not typically applied to the discipline of closure planning. Currently closure planning is often overlooked within the short-term planning and operational management decision-making processes. By linking people, process and technology in a systematic way that captures mine closure planning and integrating this into the MOS, particularly with life-of-mine planning, significant closure outcomes will be achieved, reflected in company value and ultimately sustaining the industry's social licence to operate via a positive legacy.

Keywords: system integration, resource legacy, positive legacy, negative legacy, management operating system, closure planning, people, process, technology

\section{Introduction: initiation and integration}

The impacts associated with poorly managed closure, negative closure legacy, legal liability, increasing financial costs and legal action resulting from the environmental effects of poor closure and mine transition has been a matter of escalating interest to all those stakeholders involved within the mining profession, and more broadly across the stakeholder community for some 2-3 decades. Management responses to the problem of the rapidly escalating mine closure balance sheet liabilities, steadily revealed to the sharemarket over the last decade, has recently been seen to gain real momentum, despite long standing policies to manage closure related impacts endorsed up to 25 years ago. This is taking the form of increased guidance (International Council of Mining and Metals [ICMM] 2019) initiation, appointed leaders and teams with budgets within internal company management structures to address a closure and transition response. 
However, it can be said, albeit mainly based on our experience and that of others (Grant \& Lacy 2016), that few, if any, companies have effectively brought mine closure into the heart of operational management and fully implemented the necessary businesses systems and processes to integrate mine closure to manage liabilities.

Nearly two decades ago (Lacy 2000; Australian Government 2002) the industry started to adopt mine closure guidelines stating that "mining operations needed to approach mine decommissioning and closure on a systematic basis from the very beginning of the operation" and that "mine closure planning must be a dynamic process including regular review and updating". This recognition that mine closure liabilities needed attention was supported by larger institutions such as United Nations Environment Program - Environment Security Initiative (Peck 2005) and International Council of Minerals and Metals who have reinforced these ideas with statements such as "Integrated closure planning is a dynamic process which must commence in tandem with the other planning aspects of a mining process", and recently named their most recent good practice guide 'Integrated Mine Closure' (ICMM 2003, 2006, 2008, 2019).

Concepts also repeated in the third of the Australian leading practice series emphasise integration:

- That closure activities associated with each step in the life-of-mine (LoM) cycle are integrated into business practice via the progressive implementation of a closure system.

- Systematised closure planning, as unplanned closures are not cost-effective and often result in substandard rehabilitation.

- That the implementation of progressive rehabilitation and systemised closure will result in achieving the post-mining land use and a more satisfactory social and environmental outcome; and will most importantly, sustain and enhance the standing of the mining industry (Australian Government 2016).

The lack of integration of mine closure planning into the overall business planning process in many ways is similar to the issues that historically existed with poor safety and environmental performance. The mining industry has shown that with investment and effort, particularly in use of systems, process, and culture, a paradigm shift can occur i.e. safety performance in much of the mining industry has been transformed significantly, and should be seen as a model to what we believe can be achieved with integration of mine closure into the business of mining. A clear commitment by mining leaders to closure planning processes and integrated mine closure systems, would lead to changes in policy, standards and messaging. When mining organisations), collaborate to make resources accessible to people charged with implementation, we will indeed change the mine closure paradigm (Lacy 2016).

Past efforts to integrate closure into the overall mine planning process by a handful of major mining companies have been described (Lacy 2012). BHP Billiton's and Rio Tinto's closure standards were published in 2004. Bentel (2009) stated that BHP Billiton embedded closure planning into its business systems by integrating closure into its life-of-asset planning process. In 2008 Anglo American developed and launched its mine closure toolbox. The toolbox was to help operations comply with the requirements of the Anglo Mine Closure Performance Standard and in 2017 they reported that $90 \%$ of all operations aligned with the Toolbox (Botha 2013; Anglo American 2017 p.68). However, a 2016 internal assessment to look for weakness and gaps in their process found that the lack of integration of closure planning with LoM planning was the key issue for their organisation (Grant \& Lacy 2016).

Recently we have observed large companies such as Freeport, Newmont, Teck Resources, Goldfields, and Peabody adopting a more systematic approach to the 'rehabilitation/reclamation' component of closure planning. Glencore (2018) and Hamonet (2018) describe a systematic and integrated approach to rehabilitation initiated in 2010, when the company (then Xstrata Coal) introduced 'an integrated approach involving mine planning, production and rehabilitation functions' so rehabilitation work is incorporated as far as practicable into the day-to-day operation of the mine. 
Of these companies, Anglo American has been particularly focused on this transformational process, within multiple papers presented (Grant \& Botha 2015; Grant \& Lacy 2016; Grant et al. 2016) in which they describe their progress developing an integrated closure planning system $\left(\right.$ ICPS $\left.^{\mathrm{TM}}\right)$. Notably, while promoting the development of an integrated closure planning system, they acknowledge regularly that the program will only be successful if "people, process and technology work together".

A political solution to the issue of negative legacy created by poorly closed mines has not been forthcoming, in Australia. A recently completed two-year review of mine rehabilitation and closure, found there were significant environmental and social concerns arising from legacy mining sites (Australian Senate 2019). The committee reported " it was clear that there are improvements that can be made to current industry practice and the regulatory framework underpinning mine rehabilitation", however the committee was not able to reach agreement on a unanimous set of recommendations to guide the way forward or for regulating the rehabilitation and closure of mining and resources projects. The committee summarised this large work by providing the views, and proposed recommendations, of committee members separately along party political lines. Although there is much value in the report itself, and while we acknowledge that regional, state and federal government can facilitate positive change, in this case the findings demonstrated that partisan politics effectively stifles progress in mine closure planning industry and the mining industry must lead.

Despite escalating mine closure liabilities, a broad-based solution to the problem of integrating mine closure planning into LoM operations and dealing with the problems of mine closure has yet to be embraced broadly and it is, in effect, still seen by many in the mining industry as 'someone else's problem'.

\section{$2 \quad$ Systems elements (but what is a system?)}

There are any number of definitions for systems, including "a set of things working together as parts of a mechanism or an interconnecting network; a complex whole", "collection of elements or components that are organised for a common purpose" or "a set of rules, an arrangement of things, or a group of related things that work toward a common goal" (Oxford English Dictionary 2019). Professionals working in the area of change management are more circumspect ie; believe systems thinking to be a 'holistic approach' to analysis, that focuses on the way that a system's constituent parts interrelate, how systems work over time and within the context of larger systems (Kim 1994, 1999).

Systems thinking is more than just a process, it is a discipline, with an underlying philosophy. Goodman (1997) suggests that problems that are ideal for systems thinking intervention have the following characteristics:

- The issue is important.

- The problem is chronic- and not a one time event.

- The problem is familiar and has a known history.

- People have un-successfully tried to solve the problem before.

Based on Goodmans explanation it would appear that mine closure and post-mining liabilities and integrated LoM planning would be well served by a systematic or systems thinking approach.

Systems are used widely in mining for many different purposes; early systems have been applied for more than 20 years for quality assurance in design, mine development, production, installation and servicing (AS/NZS ISO 9001), occupational health and safety (AS/NZS 4801) and in environmental management systems (ISO 14001, ISO 14004, ISO 14005, ISO 14006, ISO 14061 and ISO 14063) as well as six-sigma and other proprietary management systems.

There is an understanding in the science of system thinking that the process replaces reductionism, and is instead based on expansive thinking, analysis and synthesis. Pourdehnad identified that a core difference between system thinking and design is that effective methodologies only arise from a consideration of social systems ie. "the stakeholders are the designers" (Pourdehnad et al. 2011). Here we come to a crucial point; 
if we bring processess and technology to the problem, without due consideration, engagement and sustained involvement of people, the systematic approach will fail.

Mining systems are focused on controlling and improving 'production' processes. This is understandable as cash flow and return on investment, based on output and cost are key drivers for the business. Gradually, safety, environment and sustainability have become performance metrics and a continuous improvement philosophy is applied to most processes. A well-built system supports adaptation to circumstances that change through time; recognises that cultural change does not occur overnight, and requires integration of processes, building of engagement, breaking or softening of silos, and fostering of a sense of purpose. While some systems i.e. an assembly line, 'Just-in-Time' inventory, or 'Lean Management', are focused on productivity 'now', whereas 'integrated LoM planning' is analogous to a preventive maintenance system. A preventive system plans for and incentivises actions and behaviours now, or in the near future, with the aim of a better future outcome. Like preventive maintenance, the system the industry could seek are those that encourage the team to pay attention to the important and strategic, rather than the urgent.

\subsection{Change and its management}

Change, as we are all aware, is not easy. If there is one thing a mining operator desires, it is consistency of production, so that the operation can be fine-tuned for efficiency. However, a mine is constantly confronting change i.e. with the ore-body, the weather, regulation and the price realised when selling product. Managing all this change requires a near continuous tweaking of the few levers available to the operator and this is the work of the mining team. Integration of closure with LoM planning is a different sort of change, involving a change in culture similar to the transformation required to change safety culture, involving the tools of quality management and continuous improvement previously adopted with success by many miners. These examples point the way for implementation: it is not a foreign concept, can be done, and benefits the enterprise.

However, what is not often realised is that effective change and sustained improvement is extremely hard to attain. Few executives report that their company's transformations succeed. A global survey between 2012 and 2015 (Jacquemont et al. 2015) reported that only $26 \%$ of 4,014 executive respondents surveyed said that the transformations that they were most familiar with had been 'very', or 'completely' successful at both improving performance and equipping their organisations to 'sustain improvements over time'. Later research by the same organisation found that $74 \%$ of private-sector transformation efforts fail to meet their objectives, while in the public sector, the failure rate is even higher, at $80 \%$ (Checinski et al. 2019). In both sectors, people practices were a decisive factor, often making the difference between success and disappointment.

However, this research did evaluate the groups that 'did' achieve effective change. Twenty-four specific change actions were evaluated across five stages of transformation. The research found that organisations that took a rigorous, action-oriented approach and completed their "transformations" (initiatives that have been fully implemented), reported a $79 \%$ success rate-three times the average for all transformations (Keller \& Price 2011). Successful transformation can be attributed to five areas:

- Transformations are more likely to succeed when 'company leaders are actively involved', and sustain a positive position supporting the transformation.

- To engage employees in a transformation, companies must 'define roles' and hold initiative leaders accountable.

- When organisations follow 'a rigorous approach' to transformation and sustain energy and the action, the overall success rate improves dramatically.

- Across all the 24 transformation actions, 'communication', especially about progress, links most closely with success. 
- When organisations 'plan for continuous improvement' after a transformation, the likelihood of overall success also increases, and stagnation does not occur (adapted Jacquemont et al. 2015).

\subsection{Processes}

Mining is in itself a process. We establish systems and sub-processes to optimise the value added to the enterprise. Mine closure is also a process, but we are mistaken when we consider it to be separate. In fact, decisions made, and actions taken, during the development and exploitation of the mine have profound impact on the work to be done at closure and the value of the enterprise over the long-term.

A simple flow diagram as a representation of process (Figure 1) shows how a systems approach can bring change. The key steps include understanding the current 'As-Is' situation in the context of the desired 'to-be' state, working through input steps and activities to achieve the desired outcomes (with tracking and reporting), and measuring programme effectiveness through time to support the process. A process flow is best supported by the use of an adaptive learning loop with continuous improvement to the vision - to cement and improve the transformation.
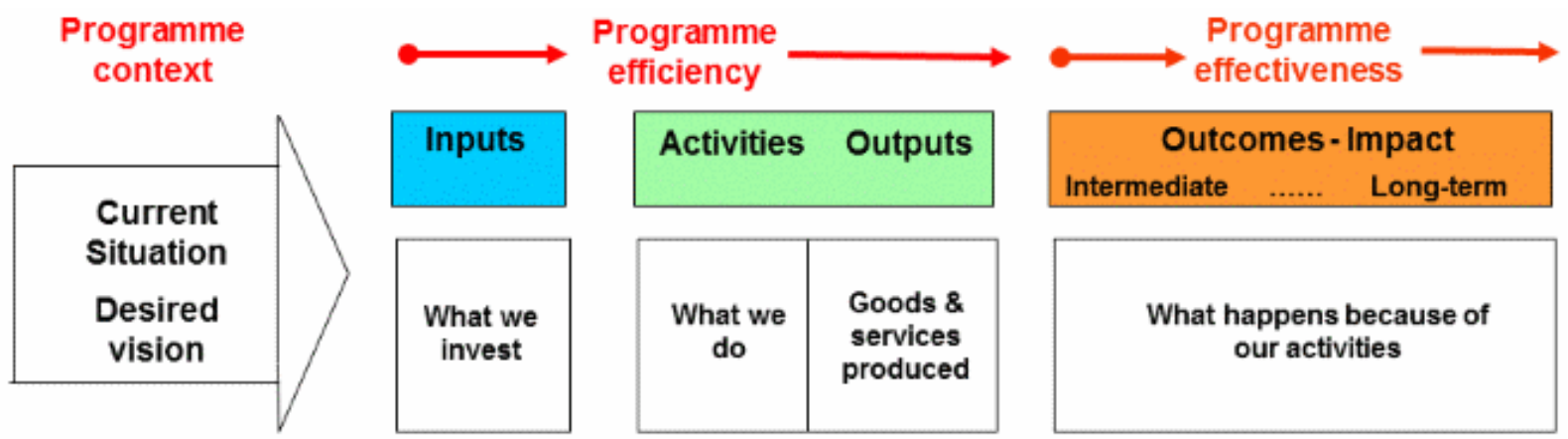

Figure 1 Representation of Process Flow to Initiate Change (from Allen \& Kilvington ca. 2019)

The mining industry has been developing processes primarily to capture and report mine closure liability, driven by financial legislation through the International Financial Reporting Standards (PWC 2007, in Slight 2015). In addition to financial drivers, government and investment compliance reporting requirements have had an effect. Society is much more aware of the post-closure cost and negative legacy associated with stabilising and closing abandoned mines, and this has translated into a significant focus on the mining industry's closure performance and cost accounting.

However, miners still rely extensively on the predictions made prior to starting up the mine and are slow to adapt the pre-mining closure plan based on the actual performance of the site. For example, a permit is granted based on the anticipated performance of a tailings storage facility liner system or the anticipated rate of drawdown of an aquifer due to the development of the open cut, yet the closed mine frequently experiences conditions quite different than those anticipated when the mine was opened, with little done in the intervening years to adapt to the actual conditions. A process that updates the closure plan and liability estimate regularly or at least make allowance for the possible range of outcomes can start to address this problem.

Integrating the mine closure and post-mining considerations into the mine plan is the most effective way to optimise enterprise value. In some countries mining companies are being forced down this path, as regulators and investing stakeholders have required each mine to have a closure plan and to provision for implementing the plan. The integration of post-mining considerations into the LoM planning process will result in investigation of the (perhaps distant) future impacts of current actions and lead to better decisions. An integrated process can provide far better accounting of the future costs, and afford the operator the opportunity to make decisions that are better for the enterprise during the operational life. 


\subsection{Technology}

We are living in a most extraordinary time as the Fourth Industrial revolution advances. Automation is already rapidly changing the face of the mining industry. Technologies such as driverless trucks, autonomous trains, sensors for automatic detection of change, collection of data through remote sensing and a digitally connected world can increasingly facilitate real-time monitoring and continuous improvement in mines. Indeed "we are at the dawn of an exciting future for the resources sector" (Clark \& Downes 2018). Yet what does this mean for mining people? When we think about the future of work in mining, it is not wise to totally defer to technology - people are still critical to instigation and implementation of effective change.

Technology is only one aspect of the solution to the challenges in integrating mine closure. We have powerful technology, that we embrace for the majority of our tasks, and which we now tend to depend on. The computing power and standardisation of platforms allows us to adopt tools in common to capture data and make estimates, such as the Standardized Reclamation Cost Estimator (SRCE) a software framework adopted for estimating closure costs. While a standard framework does impose some rigour with respect to the level of detail, the estimate might still be fundamentally wrong when the work proposed is inappropriate for the situation at that mine. While we have better, and a greater quantity of data stored in the cloud and readily accessible, the challenge to make sure it is reliable, is information of value, in making good decisions, and remains perpetually available.

We often believe that technology will resolve the problems we are confronted with; however, we suggest that addressing the other elements of an integrated system, 'people and process' is much more important to project success than selecting the 'absolutely right' technology. The 'technology' will host the integrated system that we are looking for, and it is the part of the equation that facilitates the hard work of the 'people' diligently applying the rigour of the 'process'. Equal weight of effort must be given to 'people and process'.

That being said, the tools must be adequate to task as when performance is poor and leads to a poor user experience, users will disengage from the technology and the entire endeavour and the transformation will fail.

\subsection{People (culture, engagement and terminology)}

There are five keys to the success of transformations (Figure 2), all having a strong people component, as shown by Checinski et al. (2019), and discussed, the drivers include; a clear purpose and priorities, a committed leadership, communication that is compelling, cadence i.e. 'action and coordination' in delivery, and capability or change in terms of capacity, with an equal, or predetermined application of discretionary effort.

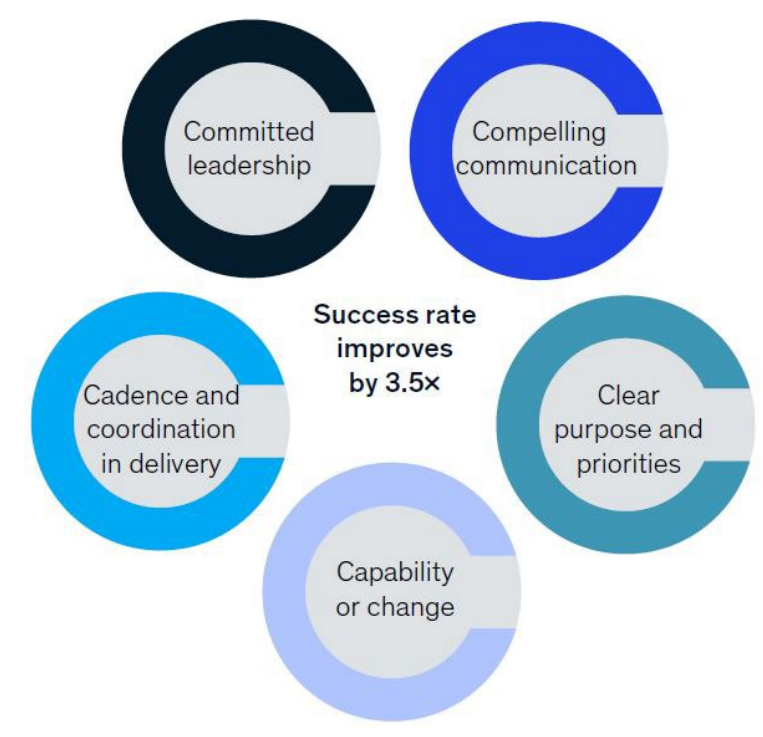

Figure 2 Five success keys for transformations (Checinski et al. 2019) 
Recent studies indicate mining professionals generally are engaged, and ready to be involved in transformational change in the industry. Early results from the online annual Mining Journal Global Leadership Survey, found that an overwhelming majority (65\%) of respondents said they were passionate about the mining sector - not just 'like it' (30\%), but 'passionate' (Global Leadership Survey 2019). The respondents identified the moral credentials of the industry as the most significant matter ahead "establishment of morally strong credentials around issues such the environment, community and general sustainability is expected to be the greatest driver of workplace transformation" (Rebecca Meeson-Frizelle pers. comm., 2 August 2019). We suggest the issues of closure planning; positive legacy and mine transition align very strongly with establishing those 'moral credentials'.

In discussing engagement during the past two decades, the lead author has been directly engaged in capacity building and leading multiple benchmarking programs responding to a specific need, or primary interest of the participants and engagement has been consistently high despite the highly varied professions of the people involved (Lacy et al. 2018). The frustration is that current mine planning tools are focused on the short-term at the expense of the longer and broader outlook. When the management system is integrated the mining professionals will have a mechanism for applying their insights and passion for the benefit of the enterprise.

To ensure success in an integrated planning system the organisational structure has to align with the planning goals and objectives, and the key questions to ask are:

- Has a structure for integrated planning been set up to achieve all business objectives, strategies and goals?

- Are the roles and responsibilities of all personnel within the organisational structure aligned to what we need to do as a business?

- Have we tried to 'fit' our structure to accommodate a 'pet' organisation structure?

The system needs to consider the following:

- There will be some people in the organisation that are doing some things that other people should be doing.

- There will be some people in the organisation that are not doing some things that they should be doing.

- There will be some people in the organisation that are doing some things that no one should be doing.

- There will be some things that no one is doing, that someone should be doing.

In making change effective; motivation, messaging and communication are critical aspects for the engagement of personnel within an organisation. Recently existing mine closure related terminology has been challenged. Alternative terminology has been suggested to replace the commonly used phrases in our field, one suggestion made is to replace 'closure planning' with the broader catch all 'Integrated Life-of-Mine (LoM) Planning'. The reasoning behind this is two-fold;

Firstly, to remove the stigma associated with the term "closure" and more accurately reflect the transformation of the disturbed area through the post-mining phase to achieve identified land-uses.

Secondly, to emphasise the importance of integrating "closure" planning into all aspects of mine planning from concept through short-term to LoM planning (Grant et al. 2018).

Another suite of terms describing goals of mine transition - such as beneficial legacy, social transition and resources legacy - are proposed (Grant et al. pp. 584 -594), legacy is one such terminology and its use requires reflection and care, as it tends to be a term used without balance by the industry, and its detractors, with solely negative connotations; however, can be defined as, 'a gift or situation that has developed as a result of past actions' (Cambridge University Press 2019). We acknowledge that depending on your particular point of view, legacy can be either positive or negative. The way the industry frames the discussion around the way in which the mineral resource legacy is described is important, framing the word as either 'positive 
or negative' provides balance. Fostering understanding of positive resource legacy in the continuing dialogue between company employees, local communities, regional stakeholders, shareholders, company managers, non-government organisations and society as a whole (Lacy \& Bennett 2015; Lacy 2016; Grant et al. 2018) results in beneficial resource legacy being recognised and acknowledged.

\section{$3 \quad$ Integration and Management Operating Systems}

Management Operating Systems (MOS) are a set of tools, communication processes and desirable management skills used to manage people and processes within the organisation to deliver results. A MOS follows the Plan, Do, Check, Act improvement cycle to achieve control of a process and steadily improve process performance. A MOS traditionally focuses on production processes and economic performance to improve productivity and lower overall cost of production.

Management processes and systems are needed to help to plan, monitor and measure events and/or processes that occur within business. We are seeing exponential growth in data analytics and monitoring as the collection, transfer, storage and analysis of data happens faster (Clark \& Downs 2018). This creates the expectation and that all mining processes are advancing this way, but it is not so with mine closure integration.

Processes in common with other industries, such as procurement, inventory management and HR obviously enjoy the benefit of a large pool of innovators. Specialty systems for mine planning and ore control, grade control and automation of the beneficiation process are real-time money-savers (i.e. in the processing of low-grade ores and by being very efficient, improved profits can be realised). It's clear though that post-closure mining liabilities have not received the same attention, simply because the benefit is to the balance sheet, not the quarterly bottom line, but in fact, any action taken now to avoid cost later is a present cost. In the worst cases the mine creates future liability through inaction today. If shareholders value a mining company primarily on current cash flow, with little attention to the underlying value of the assets, there is less financial incentive for a miner to limit the future liabilities. Whereas from the wider stakeholder perspective, there are many benefits through reducing the long-term liability, with a reduced risk of passing liabilities to unprepared owners who without adequate due diligence sometimes become bankrupt, and liability passes to the state, local community and taxpayer.

By incorporating liability management considerations in a systematic way into the regular planning of mine activities fully within an integrated closure planning process value will be realised. Currently the trend is not common across the mining business, whereas safety, environment and sustainability have become part of operational systems and are included in continuous improvement philosophies which the industry has adopted.

Currently, closure planning, with a few isolated exceptions, is mostly overlooked during the short-term planning and operational management processes, a paradigm that is considered responsible for missed opportunities, with financial, environmental and social consequenses. A shift in organisational paradigm such has occurred with safety is required to be successful in integrating mine closure into mining organisations and requires striking a balance between addressing, people, organisational process and technology, within an effective change management framework.

\section{Conclusion}

People want to do the right thing. When mining companies provide the right tools and incentivise the desired behaviour, a paradigm shift can occur. While progress is being made, the style of incentives and production pressure being imposed on miners sustain short-term thinking and there is a risk of longer-term obligations being left unmet, particularly when these are not acknowledged. What is of great concern to the authors is the lost opportunity when these obligations are not identified and mitigated within an active mine planning cycle. If the industry is to be sustainable, we need to value the enterprise over the short-term performance. 
Systems serve to guide the mine planners and provide a reliable repository for the information needed to support their decisions. When we give different groups separate systems it is unlikely, they will collaborate. If mining companies seek to transform the thinking of the mining team to include closure and post-mine management, they must integrate the systems they use. Decisions made by the short-term planners can have profound implications for the post-mining plan - good or bad. Placing closure and post-mining considerations into the day-to-day process should be normal, just as attention to concurrent preventive maintenance and worker health currently sustain a mining enterprise.

The technologies available to the mine closure practitioner are many and every day more sophisticated, but the results are dependent upon the way the tool is used. Having the tools are just a part of the solution. What is important is the experience of the user, as the success of the transformation is dependent upon the engagement of the mine organisation and all the individuals in the transformation, the most valuable being the present day, onsite miners, not some cleanup crew who follows them to a poorly abandoned mine. The transformation we seek is a broadening of the efficiency discussion, where operational efficiency embraces the very long-term including efficient wrap-up and closure of the mine.

In concluding we recall key points:

- Closure planning integrated into the mine management operating systems will provide the solution.

- The local community and regulators are key stakeholders, within a broader stakeholder group.

- Commitment of leaders is a necessity, and they must communicate that commitment - consistently.

- Adequate well-resourced budgets, for teams and tasks are required, as mine transition is a long journey.

- Internal teams lead by well-informed experienced leaders, provided with adequate authority, and skilled in change management for transformation are necessary.

- Bring the understanding of 'people, process and technology' to the transformation.

- A vision of leaving positive legacy can create a paradigm shift in mine and team engagement and will provide an effective path to mine transition.

The ideal model is where a company includes mine closure planning either within their Mine Management Operating System, or as a minimum within the LoM business processes required for the mining project, not just for approvals or the satisfying of regulatory obligations. The key to establishing an integrated system is the acknowledgement of 'change', the success of that change rests primarily with the transformational management team, who have to communicate effectively; lead actively, empower employees, and create an environment of continuous improvement.

By linking people, process and technology in a systematic way that captures mine closure planning and integrates this system into the MOS, at all levels of the organisation, then significant closure outcomes will be achieved and be reflected in positive net asset valuation of the companie. This will ultimately assist in sustaining the mining industry's inherent value and role within a much more aware and engaged $21^{\text {st }}$ century society.

\section{Acknowledgement}

The authors acknowledge the organisers of the International Mine Closure conference for providing the opportunity, Derek Vogelsang (Technology and Process Consultant), and Stantec Mining Group.

\section{References}

Allen, W \& Kilvington, M 2019, An Introduction to Systems Thinking and Tools for Systems Thinking, PowerPoint presentation, viewed 31 July 2019, http://learningforsustainability.net/wp-content/uploads/2019/01/Intro-systems-thinking-andsystemic-design-concepts-and-tools.pptx

Anglo American 2017, 'Our approach measuring our performance', Sustainability Report, p. 68, https://www.angloamerican.com/ / media/Files/A/Anglo-American-PLC-V2/documents/sustainability-report-2017.pdf 
Australian Government 2002, 'Best practice environmental management in mining - mine decommissioning', Environment Australia Best Practice Series, Canberra.

Australian Government 2016, 'Mine closure', Leading Practice Sustainable Development Program for the Mining Industry, Canberra, viewed 31 July 2019, https://www.industry.gov.au/sites/default/files/2019-04//psdp-a-guide-to-leading-practice-sustainabledevelopment-in-mining-handbook-english.pdf

Australian Senate 2019, Rehabilitation of Mining and Resources Projects and Power Station Ash Dams as it Relates to Commonwealth Responsibilities, Australian Senate, Canberra.

Bentel, GM 2009, 'Key closure planning considerations', in AB Fourie \& M Tibbett (eds), Proceedings of the Fourth International Seminar on Mine Closure, Australian Centre for Geomechanics, Perth, pp. 41-54.

Botha, PR 2013, Mine Closure Toolbox, Anglo American, Johannesburg, viewed 31 July 2019, https://www.angloamerican.com/ / media/Files/A/Anglo-American-PLC-V2/documents/approach-and-policies/environment/toolbox-main-brochure-Ir.PDF

Cambridge University Press 2019, Cambridge Dictionary, Cambridge, https://dictionary.cambridge.org/dictionary/english/legacy

Checinski, M, Dillon, R, Hieronimus, S \& Klier, J 2019, 'Putting people at the heart of public-sector transformations', Public Service Practice, occasional report, McKinsey \& Company, New York.

Clark, D \& Downs E 2018, 'What will the mine of the future be like', Aus/MM Bulletin, October, https://www.ausimmbulletin.com/ feature/will-mine-future-like/

Peck, P 2005, 'Environment security initiative mining for closure', Policies and Guidelines for Sustainable Mining Practice and Closure of Mines', Environment and Security Initiative.

Glencore 2018, Coal Mine Rehabilitation, Sydney, http://www.glencore.com.au/en/who-we-are/energy-products/Documents/ GCAA_Rehabilitation-Info.pdf

Hamonet, A 2018, Glencore's Approach to Rehabilitation, AusIMM Bulletin, October, https://www.ausimmbulletin.com/feature/ glencores-approach-rehabilitation/

Global Leadership Survey 2019, Mining Journal, Aspermont Media Ltd, London, (in draft) expected publish date 1 September 2019

Goodman, M 1997, 'Systems thinking: what, why, when, where and how', Toolbox: Systems Thinker, vol. 8, no. 2.

Grant, CD, \& Botha, PR 2015, 'Integrated closure planning: case studies on changing operational strategies to reduce closure liabilities', in AB Fourie, M Tibbett, L Sawatsky \& D van Zyl (eds), Proceedings of the Tenth International Seminar on Mine Closure, InfoMine Inc., Vancouver, pp. 92-105.

Grant, CD \& Lacy, HWB 2016, 'Developing Anglo American's integrated closure planning system; requires people, process and technology working together', in A, Fourie \& M Tibbett (eds), Proceedings of Eleventh International Seminar on Mine Closure, 15-17 March 2016, Perth, Australia, Australian Centre for Geomechanics, Perth, Australia, pp. 581 -594.

Grant, C, Lacy, HWB, Ferguson, K \& Heyes, J 2018, 'Words, words, words: But what is the matter, my closure lords', in C Drebenstedt, F von Bismarck, AB Fourie \& M Tibbett, M (eds), Proceedings of the Twelfth International Seminar on Mine Closure, Technical University Bergakademie Freiberg, Freiberg, pp. 17-24.

Grant, CD, Slight, M \& Lacy, HWB 2016, 'Integrated closure planning systems: a structured approach to opportunities analysis creates significant value', in J Wiertz \& D Priscu (eds), Proceedings of the First International Congress on Planning for Closure of Mining Operations, Gecamin, Santiago.

International Council of Mining and Metals 2003, Integrated Mine Closure, London

International Council of Mining and Metals 2006, Integrated Mine Closure, London.

International Council of Mining and Metals 2008, Planning for Integrated Mine Closure: Toolkit, L Starke (ed.), London.

International Council of Mining and Metals 2019, Integrated Mine Closure: Good Practice Guide, 2nd edition., London.

Jacquemont, D, Maor, D \& Reich, A 2015, 'How to beat the transformation odds', Occasional Report, McKinsey \& Company, New York.

Keller, S \& Price, C 2011, Beyond Performance: How Great Organizations Build Ultimate Competitive Advantage, John Wiley \& Sons, Hoboken.

Kim, DH 1994, Systems Thinking Tools: A Users Reference Guide, Pegasus Communications Inc., Encino.

Kim, DH 1999, Introduction to Systems Thinking, Pegasus Communications Inc., Encino.

Lacy, HWB 2000, 'Planning the process of closure: close as you go', Proceedings of Planning for Mine Closure - An Operator's Guide, Australian Centre for Geomechanics, Perth.

Lacy, HWB 2012, 'Environment - developments in mine closure and integration with operations in Australia', in J Rankin (ed.), Australian Mining and Metallurgical Practices in Australasia, 3rd edn, Australasian Institute of Mining and Metallurgy, Melbourne, pp. 155-161.

Lacy, HWB \& Bennett, KE 2015, ‘Updating Australia's leading practice sustainable development mine closure handbook for 2015: closing the gaps and understanding the mineral resource legacy', in AB Fourie, M Tibbett, L Sawatsky \& D van Zyl (eds), Proceedings of the Tenth International Seminar on Mine Closure, InfoMine Inc., Vancouver, pp. 71-80.

Lacy, HWB 2016, 'Seeking a paradigm shift: integrating closure planning and providing positive legacy through mine closure', in J Wiertz \& D Priscu (eds), Proceedings of the First International Congress on Planning for Closure of Mining Operations, Gecamin, Santiago, pp. 5-7.

Lacy, HWB, Grant, C, Lambrechts J \& Voigt, W 2018, 'Benchmarking; bringing the lessons from the past into the future', in C Drebenstedt, F von Bismarck, AB Fourie \& M Tibbett (eds), Proceedings of the Twelfth International Seminar on Mine Closure, Technical University Bergakademie Freiberg, Freiberg.

Oxford English Dictionary 2019, https://www.lexico.com/en/definition/system

Pourdehnad J, Wexler, ER, \& Wilson, DV 2011, 'Integrated system thinking and design thinking', System Thinker, vol. 22 , no 9.

Slight, M \& Lacy, H 2015, 'Managing and estimating closure and reclamation liabilities - a practitioners view', in RI Barnhisel (ed.), Reclamation Opportunities for a Sustainable Future, ASMR, Lexington. 